\title{
Correction to: Addressing Obsolescence from Day One in the Conceptual Phase of Complex Systems as a Design Constraint
}

\author{
Sophia Salas Cordero, Rob Vingerhoeds, Marc Zolghadri, \\ and Claude Baron
}

\section{Correction to: \\ Chapter "Addressing Obsolescence from Day One in the Conceptual Phase of Complex Systems as a Design Constraint" in: F. Nyffenegger et al. (Eds.): Product Lifecycle Management Enabling Smart X, IFIP AICT 594, https://doi.org/10.1007/978-3-030-62807-9_30}

The original version of this chapter was revised. The last name of the author Sophia Salas Cordero was incorrectly tagged. Her last name has been corrected to Salas Cordero. 